\title{
Optimized Design of Mutual Inductance Parameter in Separable Magnetic Pot Transformer used for Noncontact Energy Coupling System
}

\author{
Jinfeng LIU*, Di LU and YU ZHANG
}

\author{
School of Electrical \& Electronic Engineering, Harbin University of Science \& Technology, Harbin \\ 150040, China \\ ljf78118@163.com
}

Keywords: separable magnetic pot transformer; noncontact energy coupling; resonance compensation; optimum mutual inductance

Abstract. Energy coupling realized by separable magnetic pot transformer as new approach of rotor excitation in synchronous machine could replace brushes and slip rings of traditional excitation. For new noncontact energy coupling (NEC) system, its research about energy and efficiency quality still remains a low level because application and research of NEC aren't comprehensive, especially how to improve transmission power and efficiency is still not enough. In this paper, series \& series resonance compensation circuit was designed, and this compensation circuit would make the circuit have high transmission efficiency. Then, optimum mutual inductance was proposed. We can consider efficiency, system cost, reliability and so on based on maximum output power in order to get optimum mutual inductance. Mutual inductance coupling parameter would be optimized by adjusting structure of separable transformer and realizing optimum design of system efficiency characteristic at minimum cost. Although the output power had little increase, Ansoft 3D simulation research proved that system has high electromagnetic coupling characteristic based on optimum mutual inductance. The results of experiment also proved that efficiency of system had a quite handsome increase and verified the validity of theory analysis.

\section{Introduction}

At present, excitation systems of synchronous machines is supplied by sliding contact energy. However, this kind of method has some defects such as sliding abrasion, touching spark and carbon deposit. Therefore, new noncontact energy coupling technology has been invented to improve these detects which based on new technology about induction energy transmission theory. The character by using induction technology is the relative sites of subsystem are stable, and it can realize closed coupled and high transmission efficiency [1]. As power electronics technology, high-frequency electronic technology and magnetic materials are advancing dramatically and demands of noncontact power transfer of electrical equipments for many circumstances are increasing, this new energy transmission technology is gradually increasing [2]. The core device of this system to achieve noncontact electrical energy transmission is rotary separable magnetic pot transformer, which utilizes the benefit about transmission efficiency won't be influenced by rotate speed when primary or secondary winding of magnetic pot transformer keep rotating state. Fig. 1 shows the cross-section and overall of 3D simulation model for separable magnetic pot transformer.
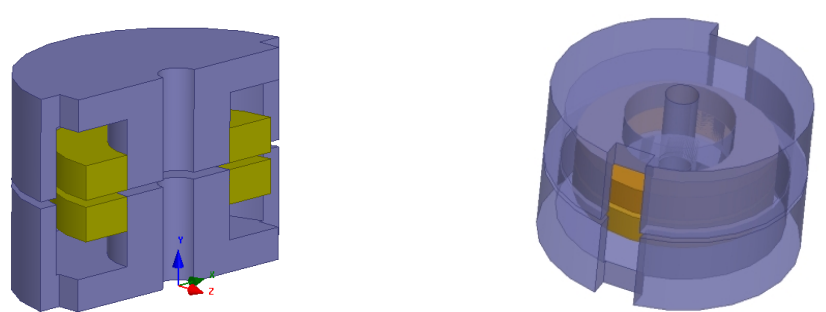

Fig.1. Simulation model for separable magnetic pot transformer. 


\section{Noncontact Energy Coupling System}

Fig. 2 is assembly drawing of the noncontact excitation energy coupling system. Secondary core of transformer, rectifier, rotor core and excitation winding are fitted on one axis. Primary core of transformer is fitted on stator of synchronous machine and controller and inverter are placed on stator cavum. The air gap between primary winding and secondary winding is controlled $0.5 \mathrm{~mm}$ to $1.5 \mathrm{~mm}$.
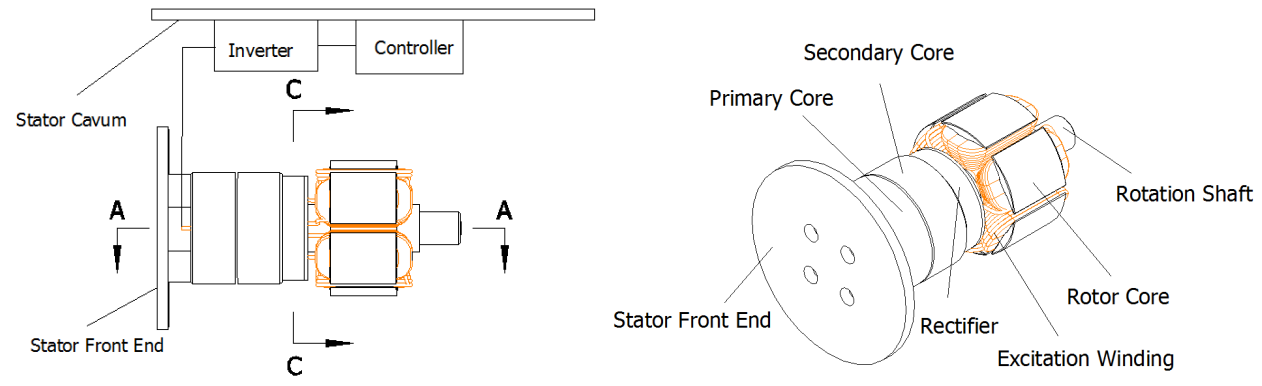

Fig.2. The assembly drawing of the noncontact excitation energy coupling system

\section{Parameters Optimized Analysis Based on Optimum Mutual Inductance}

In order to realize optimum design of system in its totality we should consider not only how to improve efficiency of system as far as possible but also various indicators such as cost, volume, reliability, withstand voltage of implements and so on based on maximum power transmission in the design process of modern electric system[3]. So the assessment function of system is no longer efficiency which is single objective function but multiple objective function which have allowed for above variables. Only realized these objective function can come to the conclusion that the system is optimum. In order to combine with variables of system we need a new assessment indicator because previous efficiency couldn't satisfy requirement[4].

It's not the most ideal result of designer that optimized mutual inductance by taking the NEC's maximum transmission power as target in design process of real system. Then a novel synthetical assessment indicator was proposed that overcame disadvantage of maximum power or efficiency as optimized factor. The output power, efficiency, cost, volume and reliability were considered in this indicator and it would optimize and analyze mutual inductance coupling parameter of system, thereby realizing overall situation optimum[5]. We can take output power of NEC's system as design target. In order to analyze easily and eliminate system output power effect of input voltage, output power must be normalized treatment. Suppose $\varphi$ as the ratio of actual output power to maximum output power, that is, $\varphi$ is load ratio of system. We take $\varphi$ as system target and load ratio \& efficiency product will be derived according to the definition.

Fig. 2 shows the mutual inductance model circuit topology of contactless transformer with series \& series harmonic compensation. Where $U_{l}$ is primary winding excitation voltage, $L_{l}$ and $L_{2}$ are primary winding inductance and secondary winding inductance respectively, $M$ is the mutual inductance of the separable transformer, $R_{1}$ and $R_{2}$ are primary winding and secondary winding resistance respectively, $R_{o}$ is the load resistance. In order to improve system performance and the ability to power transmission, the resonance compensation technology is used in primary winding and secondary winding respectively. $C_{1}$ is primary compensation capacitor and $C_{2}$ is secondary compensation capacitor.

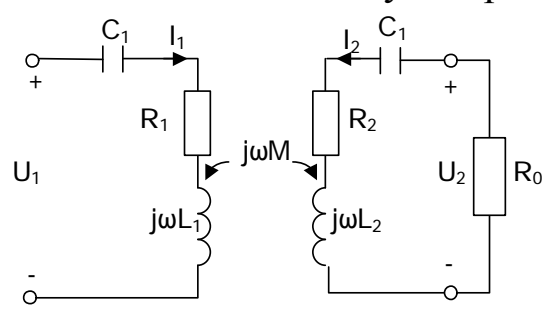

Fig. 3. Mutual inductance model of separable transformer 
System efficiency is just only $50 \%$ in series \& series harmonic compensation circuit under the maximum output power[6]. System could realize maximum output power based on optimized mutual inductance coupling parameter at the expense of dramatic decline of efficiency. In order to improve efficiency and guarantee certain transmission power, designer must increase input voltage, raise system cost and decrease reliability. While system efficiency should be improved as far as possible, cost and volume should be reduced and then reliability would be increased in the design process of real system based on certain transmission power.

Load ratio of NEC system for series \& series type on the basis of its definition is:

$$
\varphi_{s s}=\frac{4 \omega^{2} M^{2} R_{o} R_{1}}{\left(\omega^{2} M^{2}+R_{o} \mathrm{R}_{1}\right)^{2}}
$$

Then load ratio \& efficiency product is:

$$
\xi_{s s}=\eta_{s s} \times \varphi_{s s}=\frac{4 \omega^{4} M^{4} R_{o} R_{1}}{\left(\omega^{2} M^{2}+R_{o} R_{1}\right)^{3}}
$$

We could make $d \xi_{s s} / d M=0$, so we could get optimum mutual inductance and load ratio \& efficiency product would be maximum.

$$
M_{s s-\xi}=\frac{\sqrt{2 R_{o} R_{1}}}{\omega}
$$

\section{Experiment and Simulation}

Ansoft Maxwell Simulation Result. We could establish 3D simulation model of separable transformer through Ansoft Maxwell software based on the edge finite element according to design requirement of NEC and simulate in maximum output power and optimum mutual inductance, that's to say, we could contrast and analysis mutual inductance of this two kinds of indicator[7]. The frequency of input square wave voltage to primary winding is $100 \mathrm{kHz}$ and amplitude is $\pm 12 \mathrm{~V}$. Secondary winding of transformer and rotor of synchronous machine connect with same axis. The turns ratio is $1: 1$ and load resistance is $1 \Omega$. Fig. 3 and Fig. 4 are magnetic density distribution in different indicators. We could find out clearly from Fig. 3 and Fig. 4 that the magnetic density of transformer in optimum mutual inductance is higher than in maximum output power.

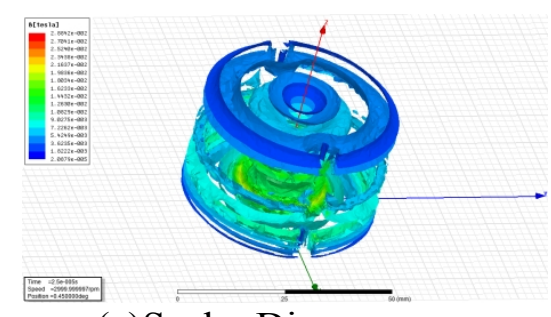

(a)Scalar Diagram

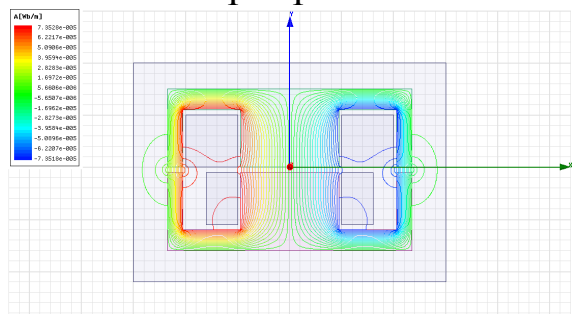

(b) Line of Magnetic Force

Fig. 4. magnetic density distribution in maximum output power

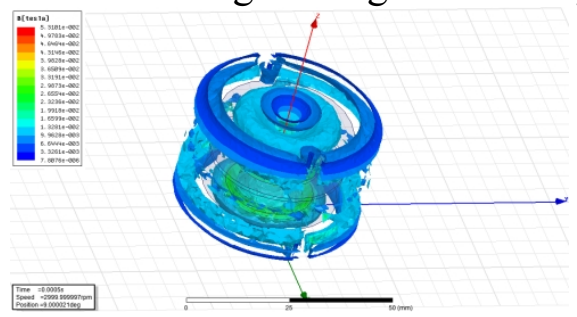

(a) Scalar Diagram

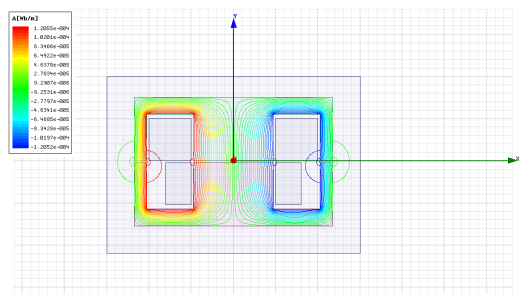

(b) Line of Magnetic Force

Fig. 5. magnetic density distribution in optimum mutual inductance 
Experiment Research. Noncontact energy coupling system was built in laboratory under the control of LM5035B in order to verify validity of optimum mutual inductance. Magnetic pot transformer and winding size are designed as follows: outside diameter $10 \mathrm{~mm} \times$ inside diameter $4 \mathrm{~mm} \times$ height $8 \mathrm{~mm}$ on core, outside diameter $9 \mathrm{~mm} \times$ inside diameter $4 \mathrm{~mm} \times$ height $8 \mathrm{~mm}$ on winding, primary number of turns and secondary number of turns are 24. It will get the parameters as follows: $L_{l}=2.76 \mu \mathrm{H}$, $L_{2}=2.63 \mu \mathrm{H}, R_{I}=R_{2}=0.26 \Omega$, Series compensation capacitor $C_{I}=C_{2}=3.67 \mu \mathrm{F}$. Then we could get resonance frequency is $50 \mathrm{kHz}$. Fig. 5 is NEC test model realized by separable transformer. The space between primary and secondary winding, revolution per minute and source frequency are all adjustable. Then the load ratio \& efficiency product parameters were obtained as shown in Table 1.

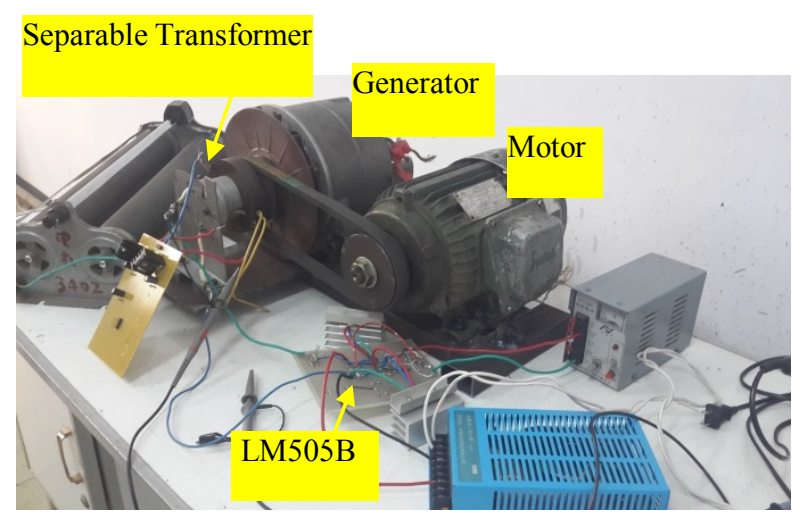

Table 1. Contrast between theory value and

\begin{tabular}{cccc}
\hline & Parameter & $\begin{array}{l}\text { Before } \\
\text { optimized }\end{array}$ & $\begin{array}{l}\text { After } \\
\text { optimized }\end{array}$ \\
\hline Theory & $I_{i}[\mathrm{~A}]$ & 7.3 & 5.2 \\
Value & $\eta[\%]$ & 47.9 & 65.4 \\
& $P_{o}[\mathrm{~W}]$ & 42 & 40.8 \\
\hline Experiment & $I_{i}[\mathrm{~A}]$ & 7.9 & 5.1 \\
Value & $\eta[\%]$ & 45.6 & 68.6 \\
& $P_{o}[\mathrm{~W}]$ & 43.2 & 42 \\
\hline
\end{tabular}

Fig. 6. Excitation system test model realized

by isolable transformer

\section{Summary}

Optimum mutual inductance indicator could get maximum load ratio \& efficiency product, realize energy transmission with high efficiency and power, reduce the investment cost, improve security of system. Then the transmission performance of NEC system achieved optimum operating point.

\section{Acknowledgments}

This project is supported by the project "New method of noncontact rotor excitation in synchronous machine", founded by the National Natural Science Foundation of China (No. 51177031) and Public Experiment of Harbin University of Science and Technology.

\section{References}

[1] Sakutaro N., Katsumi K.: submitted to Journal of IEEE transactions on Industry Applications (2000).

[2] Awai I.: IEEE International Conference on Wireless Information Technology and Systems (2010), pp.382-388.

[3] Mastri F., Costanzo A., Dionigi M.: International Microwave Workshop Series on Innovative Wireless Power Transmission(2012), pp. 245-248.

[4] Fotopoulou K.: submitted to Journal of IEEE Transactions on Magnetics (2011).

[5] Riccardo T.: submitted to Journal of IEEE Transactions on Industrial Electronics(2014).

[6] Belloumi H., Kourda F.: IEEE Mediterranean Electrotechnical Conference(2012), pp.306-311.

[7] Zhang X., Yang Q.X., Chen H.Y.: submitted to Journal of Proceedings of the CSEE(2012) (in Chinese). 